\title{
Use of pre-packaged chloroquine for the home management of presumed malaria in Malagasy children
} Arsène Ratsimbasoa ${ }^{1}$, Milijaona Randrianarivelojosia ${ }^{1}$, Pascal Millet ${ }^{3}$, Jean Louis Soarès², Leon Rabarijaona², Benjamin Rakotoson ${ }^{4}$, Denis Malvy ${ }^{3}$ and Didier Ménard*1

Address: ${ }^{1}$ Malaria Unit Research, Institut Pasteur de Madagascar, BP 1274, Antananarivo 101, Madagascar, ${ }^{2}$ Epidemiology Unit, Institut Pasteur de Madagascar, BP 1274, Antananarivo 101, Madagascar, ${ }^{3}$ EA3677, Centre René Labusquière, Université Victor Segalen Bordeaux 2, 146 rue Léo Saignat, 33076 Bordeaux Cedex, France and ${ }^{4}$ Service de Santé de District de Moramanga, Toamasina, Madagascar

Email: Arsène Ratsimbasoa - arsene@pasteur.mg; Milijaona Randrianarivelojosia - milijaon@pasteur.mg; Pascal Millet - pascal.millet@ubordeaux2.fr; Jean Louis Soarès - jlsoares@pasteur.mg; Leon Rabarijaona - leon@pasteur.mg; Benjamin Rakotoson - ipm@pasteur.mg; Denis Malvy - denis.malvy@chu-bordeaux.fr; Didier Ménard* - dmenard@pasteur.mg

* Corresponding author

Published: 14 September 2006

Malaria Journal 2006, 5:79 doi:10.1 186/1475-2875-5-79

This article is available from: http://www.malariajournal.com/content/5/I/79

(c) 2006 Ratsimbasoa et al; licensee BioMed Central Ltd.

This is an Open Access article distributed under the terms of the Creative Commons Attribution License (http://creativecommons.org/licenses/by/2.0), which permits unrestricted use, distribution, and reproduction in any medium, provided the original work is properly cited.

\begin{abstract}
Objective: The main objective of this study was to assess the quality of home malaria management with pre-packaged chloroquine in two areas in the Moramanga district of Madagascar. The knowledge, attitude and practices of care providers in terms of home treatment options were evaluated and compared. The availability of treatment options by studying retailers and communitybased service providers was also investigated.
\end{abstract}

Methods: A cross-sectional investigation in two communities, in the hamlets and villages located close to carers, retailers, community-based service providers and primary health centres was carried out.

Results: Carers in the two districts were equally well aware of the use of pre-packaged chloroquine. Their first response to the onset of fever was to treat children with this antimalarial drug at home. The dose administered and treatment compliance were entirely satisfactory $(100 \%)$ with pre-packaged chloroquine and rarely satisfactory (I.6\% to $4.5 \%)$ with non pre-packaged chloroquine. In cases of treatment failure, the carers took patients to health centres. Chloroquine was supplied principally by private pharmacies and travelling salesmen selling unpackaged chloroquine tablets. Non pre-packaged chloroquine was the most common drug used at health centres. The frequency of positive rapid malaria tests $(P=0.01)$ was significantly higher in children treated with non pre-packaged chloroquine $(38 \%)$ than in children treated with pre-packaged chloroquine (1.3\%).

Conclusion: Home malaria management should be improved in Madagascar. Efforts should focus on communication, the training of community-based service providers, access to pre-packaged drugs and the gradual withdrawal of pre-packaged chloroquine and its replacement by prepackaged artemisinin-based combination therapies. 


\section{Background}

Malaria, known locally as "tazo" or "tazomoka", is the leading cause of morbidity, mortality and hospital admission in Madagascar. Official data show a reported 2,114,400 cases of suspected malaria in 2003 (18.8\% of all outpatient visits). About 740,000 of these cases occurred in children under the age of five years [1-3]. Limited physical access to public health facilities has been recognized to limit the provision of early treatment in developing countries, such as Madagascar. As a result of this limited access, communities resort to self-medication, through the unregulated private and informal sectors [4-6]. Thus, pharmacies, medicine shops or vendors, retail shops and medicines left over in homes are often the first source of treatment when symptoms begin [7]. As most of the children who die from malaria do so within 48 hours of the onset of illness, the early use of effective antimalarial medicines in or near the home can reduce the burden of malaria in endemic areas. This acknowledged time element is critical for saving children's lives in Africa and for reducing severe malaria morbidity and mortality in nonimmune older children and adults living in other regions of the world $[8,9]$. A strong health care-delivery system should ideally provide early, reliable diagnosis and appropriate, prompt and effective treatment. However, most of those at highest risk of malaria in Madagascar live in rural areas geographically distant from health facilities (40\% of people live more than five kilometres away from the nearest health facility, including $27 \%$ more than 10 kilometres away from the nearest health facility).

In 1989, Malagasy health policy-makers decided to recommend a strategy based on the home management of malaria (HMM). This decision followed a major malaria outbreak in the mid-1980s, with the widespread distribution of chloroquine (in the form of unpackaged $100 \mathrm{mg}$ tablets). HMM was advocated as part of the National Malaria Control Programme (NMCP) in 1998. In November 2003, pre-packaged (PaluStop ${ }^{\varpi}$ ) was introduced privately by an NGO called "Population Service International" and sold at an affordable price of US $\$ 0.025$. Since March 2005, another form of pre-packaged chloroquine, Ody Tazomoka ${ }^{\circledR}$, has been freely distributed at primary public health facilities. Both presentations of pre-packaged chloroquine are available for children from six to 11 months of age (three tablets of $75 \mathrm{mg}$ ) and for children from 12 to 59 months of age (three tablets of 150 mg) (Figure 1).

The main objective of this study was to assess the quality of HMM implementation with pre-packaged chloroquine, in two areas of the Moramanga district of Madagascar (in the periurban community of Ambohibary and in the remote rural community of Lakato). The knowledge, attitude and practices of caregivers in terms of home treat- ment options (non pre-packaged and pre-packaged chloroquine) were first evaluated and compared, at community level, by interviewing carers, and at primary health centre level, by interviewing the parents or guardians of children under the age of five years consulting for fever. The malaria burden among these children was also evaluated by rapid testing. The availability of treatment options in these two areas, by studying retailers and communitybased service providers was also investigated.

\section{Materials and methods Study areas and setting}

This survey was conducted between April and June 2005, in two communities in the eastern foothills of the highlands of Madagascar: Ambohibary, a periurban community, and Lakato, a remote rural community (Figure 2).

Lakato $\left(19^{\circ} 11^{\prime} 53.7^{\prime \prime} \mathrm{S}, 48^{\circ} 23^{\prime} 32.6^{\prime \prime} \mathrm{E}\right)$, is located in a remote area 40 kilometres away from the national road connecting Antananarivo, the capital of Madagascar, to Toamasina, the main harbour on the east coast. This area is poorly accessible, especially at the beginning of the study period (rainy season), and can only be reached by poor-quality tracks. It covers an area of $702 \mathrm{~km}^{2}$ (altitude of 295 to 1,040 metres), with 15,831 inhabitants, living in 10 villages, with 44 hamlets. There is one "level two" primary health centre (CSB2: "centre de santé de base niveau 2", managed by a physician) and two "level one" primary health centres (CSB1: "centre de santé de base niveau 1" managed by a nurse). The prevalence of malaria in children under five years of age in this district has been estimated at 30\%, with peaks in April-May and SeptemberOctober (Malagasy Ministère de l'Intérieur et Collectivité territoriale for the district of Moramanga, 2005).

Ambohibary ( $\left.18^{\circ} 54^{\prime} 55.5^{\prime \prime} \mathrm{S}, 48^{\circ} 13^{\prime} 39.3^{\prime \prime} \mathrm{E}\right)$ is located in a periurban area seven kilometres from the urban centre of Moramanga. It covers an area of $729 \mathrm{~km}^{2}$ (altitude of 910 to 1,040 metres), with 16,557 inhabitants living in nine villages with 50 hamlets. It has one level 2 primary health centre and two level 1 primary health centres. The prevalence of malaria in children under five years of age in this district has been estimated at $27 \%$, with a peak in April-May (data from the Malagasy Ministère de l'Intérieur et Collectivité for the district of Moramanga, 2005).

\section{Sampling methods and data collection}

A cross-sectional investigation in the two communities, focusing on carers, drug sellers and community-based service providers and primary health centres in the hamlets and villages was carried out.

A two-level cluster sampling for the investigation of carers was used. A questionnaire was designed to collect data on knowledge, attitudes, practices and beliefs (KAPB) relat- 


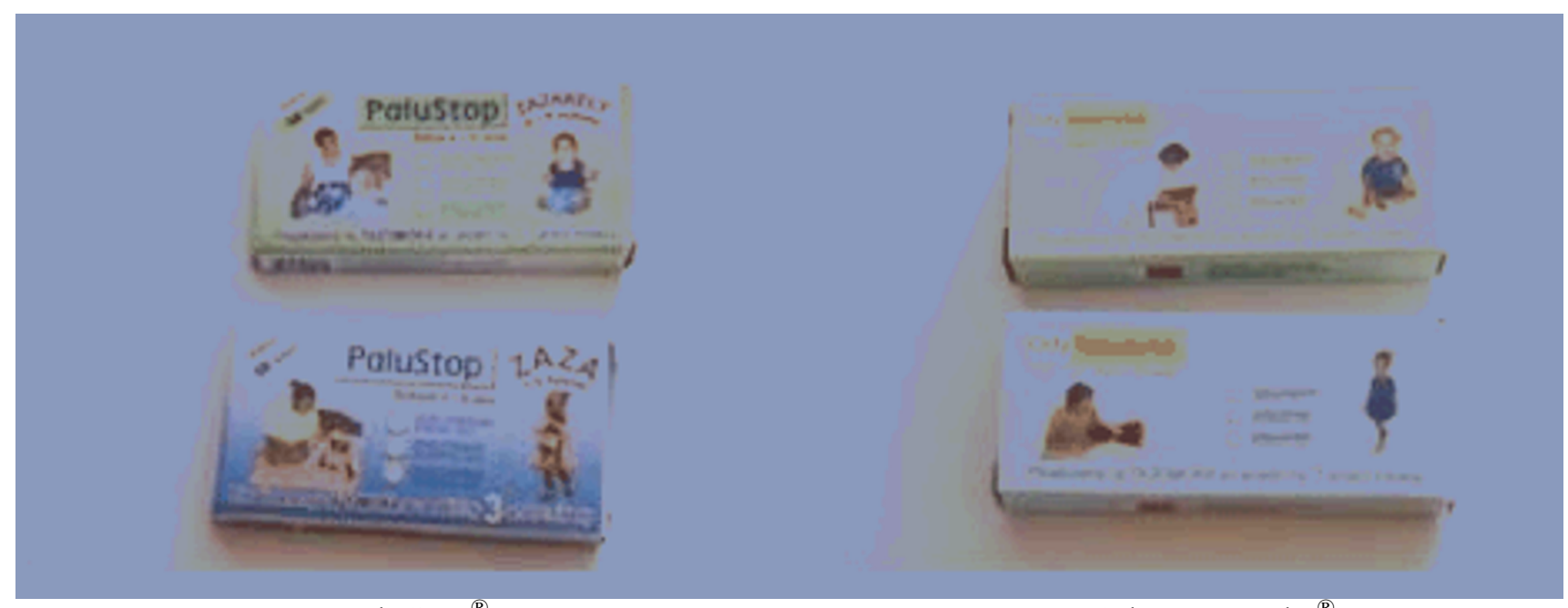

PaluStop $\left.^{(}\right) \quad$ Ody Tazomoka $\left.{ }^{(}\right)$
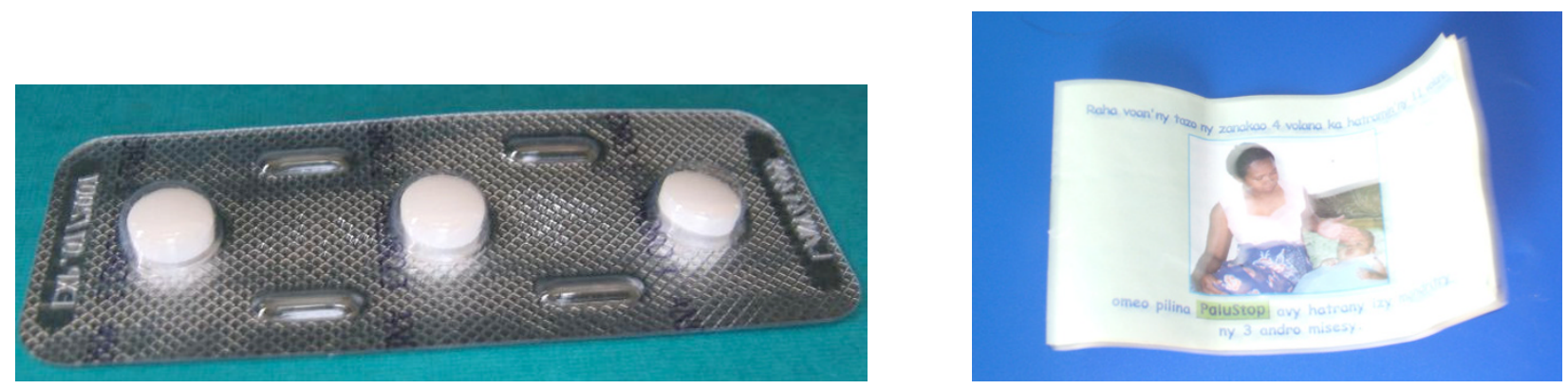

\section{Figure I}

Pre-packaged chloroquine (PaluStop ${ }^{\circledR}$ and Ody Tazomoka ${ }^{\circledR}$ ) used for HMM in Madagascar (green boxes: for children aged 6 to $1 \mathrm{l}$ months, 3 pills of $75 \mathrm{mg}$, and blue boxes: for children from 12 to 59 months, 3 pills of $150 \mathrm{mg}$ ).

ing to malaria. This questionnaire was tested on 21 carers, to determine the frequency of knowledge relating to HMM. The minimum sample size required for the carer investigation was estimated at 392 (with 95\% confidence intervals). Four hundred twenty carers (30 clusters of 14 carers) were finally included. All villages were informed one day before the investigation, by the head of the district. Each interviewer worked with a guide, who introduced him at each village. On the day of the investigation, the objectives of the study were explained to the children's carers before the interview. Carers were included in the study after they provided written informed consent. During the investigation, the interviewers were provided with questionnaires and pre-packaged chloroquine (PaluStop ${ }^{\circledast}$ and Ody Tazomoka ${ }^{\circledR}$ ). If the carers said that they had used pre-packaged chloroquine, they were asked to indicate the presentation used: PaluStop ${ }^{\circledast}$ or Ody Tazomoka ${ }^{\circledast}$. The investigator also checked whether insecticide-impregnated bed nets were used.

In Ambohibary and Lakato, all drug retailers and community-based service providers were interviewed with a designed questionnaire, after they had given written informed consent.

At primary health centres (three in Ambohibary and three in Lakato), all children under the age of five, clinically suspected of malaria (fever and recent history of fever) were enrolled and their parents or guardians were interviewed after they had provided written informed consent. Questionnaires were completed by health workers. The investigator carried out a rapid diagnostic test (OptiMal-IT ${ }^{\circledR}$, DiaMed, Switzerland) to confirm the diagnosis of malaria and checked that the questionnaire had been completed 


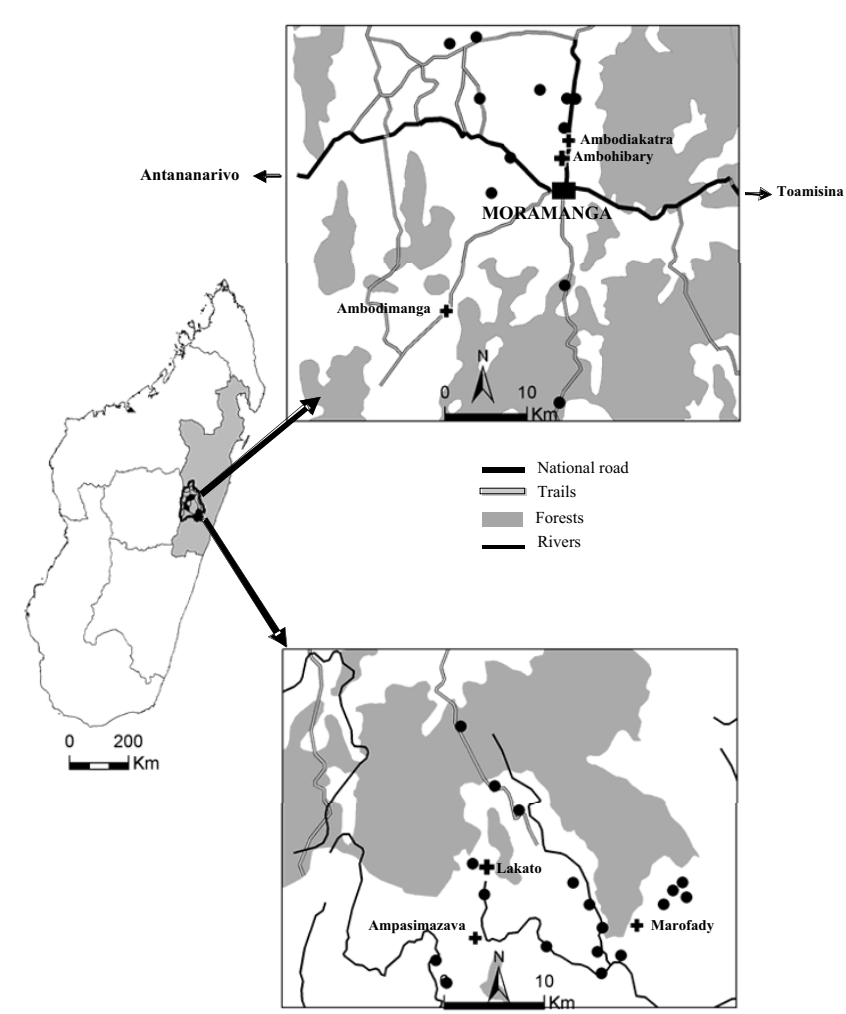

Figure 2

Map of the Moramanga District (with primary health centres).

correctly. The results of the rapid tests for malaria were communicated to the head of the primary health centre.

\section{Data analysis}

Data were entered, processed and analysed with EpiInfo software (CDC, version 3.3.2). Chi-squared tests were used to assess the significant of differences between proportions. For continuous data, the significance of differences was assessed using Student's t-tests or KruskalWallis tests.

\section{Results}

The study was carried out in 27 hamlets and villages (13 in Ambohibary and 14 in Lakato). At the community level, 420 carers (196 in Ambohibary and 224 in Lakato), 10 community-based service providers ( 6 in Ambohibary and 4 in Lakato) and 32 retailers (22 in Ambohibary and 10 in Lakato) were interviewed. At primary health centre level, 341 patients attended health centres (109 in Ambohibary and 232 in Lakato), of which 207 children under the age of five, clinically suspected of malaria, were enrolled in the study (60 in Ambohibary and 147 in Lakato).

\section{Investigation of carers}

More than $95 \%$ of the 420 carers interviewed were the mothers of the patients concerned. The youngest carer was 15 years old, the oldest was 65 years old and the median age of the carers was 29 years. Three-quarters $(79.1 \%$ in Ambohibary and $69.2 \%$ in Lakato) of carers were married, or cohabited with a partner, the remaining carers being single, divorced, separated or widowed. The mean number of children under the age of five years looked after by an individual carer was significantly higher in Lakato (1.6) than in Ambohibary (1.4) $(P=0.0026)$. Significant differences were also found between the two districts in terms of professional activity $\left(\mathrm{P}<10^{-6}\right)$ : 90.6\% farmers in Lakato and 54.6\% farmers in Ambohibary, with $19.4 \%$ craftsmen in Ambohibary and $0.4 \%$ in Lakato. Educational status profiles also differed significantly between Ambohibary and Lakato ( $P=0.00005)$ : no formal education (15.3\% in Ambohibary and 42\% in Lakato), primary education (51.5\% in Ambohibary and $39.3 \%$ in Lakato), and secondary or further education (33.1\% in Ambohibary and $18.8 \%$ in Lakato). The distance from the hamlet or village to the nearest health centre also differed significantly $\left(\mathrm{P}<10^{-6}\right)$ between Ambohibary and Lakato (Table 1). More than two-thirds of the carers in Ambohibary lived less than two hours walk from the nearest health centre, whereas more than two-thirds of the carers in Lakato lived more than two hours walk from the nearest health centre.

The carers' knowledge about malaria was assessed (Table 2). Carers in Ambohibary were significantly better informed about malaria transmission than their counterparts in Lakato. In Ambohibary, carers were as familiar with PaluStop ${ }^{\circledR}$ as with Ody Tazomoka ${ }^{\circledR}$, whereas carers in Lakato were more familiar with PaluStop ${ }^{\circledR}$, because this form of pre-packaged chloroquine was distributed freely in this area by and NGO.

The management of uncomplicated childhood fever by carers in Ambohibary and Lakato is detailed in Table 3. In most cases, carers in both areas initially reacted to the onset of fever by treating the child with an antimalarial drug at home. However, in the rural area of Lakato, traditional treatment was widespread and used by more than one quarter of carers (bitter plants such as Exacum sp, from the Gentianaceae family, known as "felatanandraka" or "aferontany" in Malagasy). In most cases, the plant concerned was gathered, prepared and administered directly by the carer. The reasons for administering antimalarial drugs at home, according to carers, differed slightly between the two areas: (i) in Ambohibary, the first reason given by carers was that they already had such drugs at home (46.8\% non pre-packaged chloroquine and 53.2\% pre-packaged chloroquine), the second reason was that they had enough money to pay for a consultation with a 
Table I: The distances (walking times) between the villages and hamlets and the nearest health centre in the Ambohibary and Lakato areas (District of Moramanga, Madagascar)

\begin{tabular}{|c|c|c|c|}
\hline \multirow[b]{2}{*}{$\begin{array}{l}\text { Distance between the villages and the nearest health } \\
\text { centre (in time) }\end{array}$} & \multicolumn{2}{|c|}{ Areas } & \multirow[b]{2}{*}{$P\langle$ chi 2> } \\
\hline & Ambohibary $n=196 \%(\mathrm{Cl} 95 \%)$ & Lakato $n=224 \%(\mathrm{Cl} 95 \%)$ & \\
\hline 0 to 30 minutes & $29.1(22.8-36)$ & $11.6(7.7-16.5)$ & $<10^{-6}$ \\
\hline 30 to 60 minutes & $35.7(29-42.9)$ & $4.5(2.2-8.1)$ & \\
\hline I to 2 hours & $13.8(9.3-19.4)$ & $7.1(4.1-11.3)$ & \\
\hline 2 to 3 hours & $20.9(\mid 5.4-27.3)$ & $40.2(33.7-46.9)$ & \\
\hline 3 to 4 hours & $0(0-1.9)$ & $14.3(10-19.6)$ & \\
\hline More than 4 hours & $0.5(0-2.8)$ & $22.3(17-28.3)$ & \\
\hline
\end{tabular}

health worker and the third reason was that the health centre was too far away; (ii) in Lakato, the two most important reasons given by carers were that they already had drugs at home (42.8\% non pre-packaged chloroquine and $57.2 \%$ pre-packaged chloroquine), and the health centre being too far away. The third reason given was that there were often no health workers at the health centre. Regardless of the location, it was observed that the further the distance between the village and the health centre, the more likely the carer was to use antimalarial drugs at home (at Ambohibary, 66\% for carers less than one hour from the health centre and $86 \%$ more than one hour from the health centre used antimalarial drugs at home; at Lakato, $83 \%$ of carers living less than one hour from the health centre and $97 \%$ living more than one hour from the health centre used antimalarial drugs at home). Conversely, the frequentation of health centres decreased with distance from the village, from $34 \%$ to $13 \%$ in Ambohibary and from $17 \%$ to $3 \%$ in Lakato.

In both areas, the dose administered and treatment compliance were entirely satisfactory $(100 \%)$ with pre-pack- aged chloroquine treatment (PaluStop ${ }^{\circledR}$ or Ody Tazomoka $^{\circledR}$ )and rarely satisfactory (1.6\% to $\left.4.5 \%\right)$ with non pre-packaged chloroquine treatment. The carers took a mean time of 3.5 days (3.7 in Ambohibary and 3.3 in Lakato) to evaluate the efficacy of treatment. In case of treatment failure (persistence of malaria symptoms), the carers in both communities took the patient to a health centre.

\section{Investigations of retailers and community-based service providers}

Chloroquine was supplied principally by private pharmacies and travelling salesmen in the two areas. In the periurban area of Ambohibary and in the remote area of Lakato, health workers were responsible for educating carers, providing them with sufficient information to enable them to recognize the clinical symptoms of malaria, to assess its severity and to take appropriate action.

Unpackaged chloroquine tablets were sold more frequently than pre-packaged chloroquine tablets to carers by retailers and salesmen. The carers often bought an

Table 2: Carers' knowledge about malaria in the Ambohibary and Lakato areas (District of Moramanga, Madagascar)

\begin{tabular}{|c|c|c|c|c|}
\hline \multirow[b]{2}{*}{ Variable } & \multirow[b]{2}{*}{ Results } & \multicolumn{2}{|c|}{ Areas } & \multirow[b]{2}{*}{$P<$ chi 2> } \\
\hline & & $\begin{array}{l}\text { Ambohibary } \\
\text { No (\%) }\end{array}$ & $\begin{array}{l}\text { Lakato } \\
\text { No (\%) }\end{array}$ & \\
\hline Recorded symptoms & $\begin{array}{l}\text { Fever alone or in combination with others } \\
\text { symptom* }\end{array}$ & $195(99.5)$ & $223(99.5)$ & NS \\
\hline \multirow[t]{3}{*}{ Knowledge of malaria transmission } & By mosquitoes & $144(73.5)$ & $73(32.6)$ & $<10^{-4}$ \\
\hline & By other ways & $23(11.7)$ & $23(10.3)$ & NS \\
\hline & None & $29(14.8)$ & $128(57.1)$ & $<10^{-3}$ \\
\hline \multirow{3}{*}{$\begin{array}{l}\text { Malaria prevention used for children under } \\
5 \text { years }\end{array}$} & Chloroquine & $3(1.5)$ & $3(1.3)$ & NS \\
\hline & Impregnated bed nets & $63(35.2)$ & $78(34.8)$ & NS \\
\hline & None & $124(63.2)$ & $143(63.8)$ & NS \\
\hline \multirow{2}{*}{$\begin{array}{l}\text { Knowledge of the use of pre-packaged } \\
\text { chloroquine }\end{array}$} & PaluStop ${ }^{\circledR}$ & 140 (7I.4) & $171(76.1)$ & NS \\
\hline & Ody Tazomoka ${ }^{\circledR}$ & $137(69.9)$ & $65(29.0)$ & $<10-6$ \\
\hline
\end{tabular}

*Sweating, red eyes, shivering, joint pain, dizziness, cough, diarrhoea, runny nose, anorexia, vomiting 
Table 3: Carer's management of uncomplicated childhood fever in the Ambohibary and Lakato areas (District of Moramanga, Madagascar)

\begin{tabular}{|c|c|c|c|c|}
\hline \multirow{3}{*}{ Variable } & \multirow{3}{*}{ Results } & \multicolumn{2}{|c|}{ Areas } & \multirow{3}{*}{$P\langle$ chi $2>$} \\
\hline & & \multirow{2}{*}{$\frac{\text { Ambohibary }}{\text { No (\%) }}$} & \multirow{2}{*}{$\frac{\text { Lakato }}{\text { No (\%) }}$} & \\
\hline & & & & \\
\hline \multirow[t]{4}{*}{ Action of the carer at fever onset } & Went to clinic/health centre & $52(26.5)$ & $24(10.7)$ & $<10^{-5}$ \\
\hline & Used antimalarial drugs at home (self-treatment) & $139(70.9)$ & $138(61.6)$ & 0.05 \\
\hline & Used herbal medicines & $5(2.5)$ & $57(25.4)$ & $<10^{-6}$ \\
\hline & Went to traditional healer & $0(0)$ & $5(2.2)$ & NS \\
\hline \multirow{4}{*}{$\begin{array}{l}\text { Reasons given by carers for use of } \\
\text { antimalarial drugs at home }\end{array}$} & No health worker at health centre & $0(0)$ & $46(20.5)$ & $<10^{-6}$ \\
\hline & No money to pay for consultation & $5 \mathrm{I}(25.7)$ & $31(13.8)$ & 0.002 \\
\hline & Long distance to health centre & $29(14.6)$ & $73(32.8)$ & $<10^{-4}$ \\
\hline & Correct treatment known/Drugs already at home & $117(59.7)$ & $74(32.9)$ & $<10^{-6}$ \\
\hline \multirow[t]{3}{*}{ Antimalarial drugs used at home } & Not pre-packaged chloroquine & $65(46.8)$ & $59(42.8)$ & NS \\
\hline & PaluStop ${ }^{\circledR}$ & $50(36.0)$ & $2(1.4)$ & NS \\
\hline & Ody Tazomoka ${ }^{\circledR}$ & $24(17.2)$ & $77(55.8)$ & 0.007 \\
\hline \multirow{3}{*}{$\begin{array}{l}\text { Correct dose of chloroquine administered by } \\
\text { carer }\end{array}$} & Non pre-packaged chloroquine & $\mathrm{I}(\mathrm{l} .5)$ & I ( 1.6$)$ & NS \\
\hline & PaluStop ${ }^{\circledR}$ & $50(100)$ & $2(100)$ & NS \\
\hline & Ody Tazomoka ${ }^{\circledR}$ & $24(100)$ & $77(100)$ & NS \\
\hline \multirow[t]{4}{*}{ Action after treatment failure } & Went to community-based service provider & $7(3.6)$ & $24(11)$ & NS \\
\hline & Went to clinic/health centre & $186(94.9)$ & $164(73.0)$ & $<10^{-6}$ \\
\hline & Used herbal medicines & $0(0)$ & $6(3.0)$ & - \\
\hline & Went to traditional healer & $3(1.5)$ & $30(13.0)$ & NS \\
\hline
\end{tabular}

insufficient amount of chloroquine (two to four $100 \mathrm{mg}$ tablets in Ambohibary and two to three $100 \mathrm{mg}$ tablets in Lakato). A single tablet of $100 \mathrm{mg}$ non pre-packaged chloroquine was sold at the same price as an entire box of prepackaged chloroquine (full treatment for a child under five). Chloroquine often seemed to be in short supply in both areas.

Four retailers and salesmen in Ambohibary (18\%) and two retailers in Lakato $(20 \%)$ sold pre-packaged chloroquine (PaluStop ${ }^{\circledast}$ ). This brand of chloroquine has been available for 12 months in Ambohibary and 10 months in Lakato.

Ody Tazomoka ${ }^{\circledR}$ was distributed freely by the six community-based service providers in Ambohibary $(100 \%)$ and by only one such service provider in Lakato $(25 \%)$. This drug only became available a few weeks before the start of the study.

\section{Primary health centre investigations}

Of the 207 children under five years of age seen at health centres (60 in Ambohibary and 147 in Lakato), 50\% were initially treated at home in Ambohibary and $27.2 \%$ in
Lakato. The mean time between the onset of fever and consultation at a health centre was two days in Ambohibary (0 to 6 days) and three days in Lakato (0 to 14 days).

In both areas, non pre-packaged chloroquine was the drug most frequently used for treatment at home $(53.7 \%$ in Ambohibary and 50.8\% in Lakato). Pre-packaged chloroquine was used less frequently (19.6\% in Ambohibary and $10.4 \%$ in Lakato). Of the 70 children treated with chloroquine at home, 55 were treated with non pre-packaged chloroquine and 15, with pre-packaged chloroquine. Rapid tests for malaria were positive in $40 \%$ of cases in Ambohibary and $45 \%$ of cases in Lakato. The frequency of positive rapid tests for malaria $(\mathrm{P}=0.01)$ was significantly higher for children treated with non pre-packaged chloroquine (38\% positive rapid tests overall, $18 \%$ in Ambohibary and $52 \%$ in Lakato) than for children treated with pre-packaged chloroquine $(1.3 \%$ positive rapid tests overall, 2\% in Ambohibary and $0 \%$ in Lakato).

\section{Discussion}

The success of health interventions such as HMM requires communities to have detailed knowledge of perceived 
health problems [10]. These health problems can only be recognized as amenable to modern health interventions if their manifestations are perceived as being amenable to modern treatment [11]. In Ambohibary and Lakato, malaria is the most common health problem in childhood. The prevalence of malaria in children under the age of five in the health centres of these two areas is similar to national estimates [2]. Thus, these communities are willing to participate in health interventions aiming to reduce the frequency of malaria in their children.

This study was carried out in two areas with different socio-demographic profiles, representative of the current situation in Madagascar. In these two areas, most of the carers were mothers, as reported in other areas of Madagascar [11] and in Africa $[12,13]$. The mother's ability to associate malaria with fever has important implications for the survival of her child in areas of endemic malaria $[14,15]$. In Ambohibary as well in Lakato, investigation of carers showed $99.5 \%$ of them identified malaria as fever alone or in combination with other symptoms such as sweating, red eyes, shivering, headache, joint pain, dizziness, cough, diarrhoea, runny nose, anorexia or vomiting. This frequency is higher than that reported in other studies: $85.6 \%$ in the Democratic Republic of Congo [16] and $80.8 \%$ in Burkina Faso [17].

In the two areas studied, mothers faced with a case of suspected malaria in one of their children chose first to administer antimalarial drugs at home, seeking care for their child at a health facility only in case of treatment failure. This shows that mothers have the potential to manage malarial fever correctly at home and to consult health workers. These positive attitudes and practices should be reinforced during health interventions, to decrease severe morbidity and mortality from childhood malaria by improving case management. However, even in Ambohibary, where the mothers knew that malaria was transmitted by mosquitoes, only one third of the children slept under insecticide-impregnated bed nets. Although many mothers were aware of pre-packaged chloroquine $(69.9 \%$ in Lakato and $76.1 \%$ in Ambohibary) only half of them used it, often because they had the drug in an non-packaged form at home. This was the case in the periurban area of Ambohibary, where the flow of information about HMM strategy and the supply of pre-packaged chloroquine are easy to establish. In this area, either information about the HMM strategy was not transmitted by health workers due to a lack of motivation, or carers chose not to use the free pre-packed chloroquine because they thought that it was not effective. In the remote area of Lakato, the main reason for not using pre-packaged chloroquine was the time lag to the release of free pre-packaged chloroquine, because of a lack of co-ordination between the communities and the headquarters of the district health authority.

Chloroquine was introduced into Madagascar in 1945 and is the antimalarial drug best known to the Malagasy people $[18,19]$. As previously reported in Madagascar [11] and Nigeria [20], non pre-packaged tablets were not used appropriately in either Ambohibary or Lakato. In these two areas, the use of non pre-packaged chloroquine by carers led to a significantly higher rate of treatment failure, as shown in this study for health centre-based analyses. By contrast, all carers using pre-packaged chloroquine used this drug at the correct dose. For HMM to be effective, the population must be aware of: (i) the correct dose and (ii) the need to complete treatment (drug resistance often develops because the course of treatment is not completed). The easy-to-follow leaflet, with illustrations on the box and the blister-packed tablets may also have encouraged carers to use pre-packaged chloroquine. Similarly, in Uganda [21], mothers favoured pre-packaged chloroquine, known as "homapak", because it was neatly and attractively packaged. A decrease in the efficacy of chloroquine against $P$. falciparum has recently been recorded in several areas $[22,23]$. Based on these findings, the Malagasy Ministry of Health could improve HMM by withdrawing pre-packaged chloroquine, gradually replacing it with pre-packaged artemisinin-based combination therapies (ACT, such as artesunate plus amodiaquine, the first-line treatment recommended for uncomplicated malaria in Madagascar in the forthcoming revised national policy. ACT acts more rapidly, has a higher cure rate and causes fewer side-effects than other treatment, such as chloroquine, but is more expensive.

However, if pre-packaged drugs are to be used, efforts are required: (i) to ensure effective communication, favouring correct care-seeking behaviour and appropriate and effective HMM for the treatment of febrile illness. Particular attention should be paid to stressing the link between mosquitoes and malaria for less literate carers, and the importance of prompt and complete treatment with prepackaged drugs; (ii) to train community-based service providers, to ensure that they have the necessary skills and knowledge to manage febrile illness or malaria. This training could take place within the commercial sector, but might then have to be based on a limited curriculum, dictated by the amount of time that trainers are willing to spend without compromising their own businesses; (iii) to supervise and monitor implementation activities at the community and health facility levels.

\section{Authors' contributions}

$A R, M R$ and DMe were involved in all stages of this study. PM, JLS and LR were involved in the design of the study. $\mathrm{BR}$ participated in the coordination of the field work. 
DMa helped to compose the manuscript and gave constructive advice.

\section{Acknowledgements}

We thank all the carers, retailers, community-based service providers and health workers in health centres in Ambohibary, Lakato, Marofody, Ampasimazava, Ambodiakatra, Ambohitranjavidy, Ambodimanga Bac, Tiasoa Andriamiandranoro, Nofoniaina and the guides for their co-operation and participation. We thank the staff of the "Groupe de Recherche sur le Paludisme de l'Institut Pasteur de Madagascar", and, in particular, Dr Frédéric Ariey, Dr Lucie Raharimalala, Dr Olivier Domarle, Dr Fanjasoa Rakotomanana, Dr Marie Ange Rason, Dr Rindra Randremanana, Dr Arthur Randriamanantena, Dr Laurence Randrianasolo, Mlle Lantosoa Rasolofoharinoro, Mr Tianaso Andriamiandranoro, Mr Rogelin Raherinjafy, Mr Angelo Ramahavalisoa, the staff of "Moyens généraux de I'Institut Pasteur de Madagascar" (Joseph Andrianasy, Olivier Randriambololona, Alfred Rakotoarinelina, Désiré Rakotonivelo), Dr Antoine Talarmin and Dr Philippe Mauclère, Directors of the Institut Pasteur de Madagascar, Dr Milasoa Mosa, Head of the "Direction des Urgences et de la Lutte Contre les Maladies Transmissibles du Ministère de la Santé et du Planning Familial" of Madagascar, Dr Philémon Tafangy, Head of the "Service de Lutte Contre le Paludisme du Ministère de la Santé et du Planning Familial" of Madagascar and to the Moramanga District Administration for logistic support. We thank the teaching and training staff of the Centre René-Labusquière (Tropical Medicine and International Health Branch), EA 3677, University of Bordeaux 2.

This study received financial support from the Direction des Affaires Internationales du Réseau International des Instituts Pasteur, from the French Government via the FSP/RAI 200I-168 project (French Ministry of Foreign Affairs), from the Global Fund to Fight AIDS, Tuberculosis and Malaria round 3 grant MDG-304-G05-M and from the Institut Pasteur de Madagascar.

\section{References}

I. Institut National de la Statistique de Madagascar: Enquête auprès des Ménages. 2002:7I-83.

2. Jeremiah M, Sulhuan A, A A: Mortalité des enfants de moins de 5 ans à Madagascar. Enquête Démographique et de la Santé III à Madagascar 2004:191-201.

3. UNICEF: Multiple Indicator Cluster Survey (MICS). 2004 [http://www.childinfo.org/MICS2/newreports/madagascar/madagas car.pdf.].

4. Baume C: Comparing care-seeking for childhood malaria: lessons from Zambia and Kenya. Airlington, Basic support for Institutionalizing Child Survival (BASICS II) for the United States Agency for International Development 2002.

5. Salako LA, Brieger WR, Afolabi BM, Umeh RE, Agomo PU, Asa S, Adeneye AK, Nwankwo BO, Akinlade CO: Treatment of childhood fevers and other illnesses in three rural Nigerian communities. J Trop Pediatr 200I, 47:230-238.

6. Yeung S, White NJ: How do patients use antimalarial drugs? A review of the evidence. Trop Med Int Health 2005, I0:121-I38.

7. McCombie SC: Treatment seeking for malaria: a review of recent research. Soc Sci Med 1996, 43(6):933-945.

8. Lepers JP, Andriamangatiana-Rason MD, Ramanamirija JA, Fontenille $D$, Lepers $C$, Deloron P, Coulanges P: [Malaria in 1988 in a village of the Malagasy Highland Plateaux. Epidemiological findings]. Arch Inst Pasteur Madagascar 1989, 56:97-130.

9. Newton CR, Krishna S: Severe falciparum malaria in children: current understanding of pathophysiology and supportive treatment. Pharmacol Ther 1998, 79:1-53.

10. Mwenesi HA: The role of drug delivery systems in health care: the case of self- medication. Afr J Health Sci 1994, I:42-48.

II. Ravaoarivelo J: Prise en charge du paludisme en milieu rural à Bealanana. Institut National de la Santé Publique et Communautaire, Madagascar 1999.
12. Kilian $A H$, Tindyebwa $D$, Gulck $T$, Byamukama W, Rubaale $T$, Kabagambe G, Korte R: Attitude of women in western Uganda towards pre-packed, unit-dosed malaria treatment for children. Trop Med Int Health 2003, 8:43I-438.

13. Njama D, Dorsey G, Guwatudde D, Kigonya K, Greenhouse B, Musisi $S$, Kamya MR: Urban malaria: primary caregivers' knowledge, attitudes, practices and predictors of malaria incidence in a cohort of Ugandan children. Trop Med Int Health 2003, 8:685-692.

14. Gomes M, Espino FE, Abaquin J, Realon C, Salazar NP: Symptomatic identification of malaria in the home and in the primary health care clinic. Bull World Health Organ 1994, 72:383-390.

15. Schapira A: A standard protocol for assessing the proportion of children presenting with febrile diseases who suffer from malaria disease. WHO/MAL/94I 069 World Health Organization, Geneva; 1994

16. Talani P, Samba G, Moyen G: [Management of child fever in the battle against malaria in Brazzaville]. Bull Soc Pathol Exot 2002, 95:47-49.

17. Drabo K, Tarnagda Z, Zeba A: Représentations et pratiques en matière de paludisme chez les personnes en charge des enfants de moins 5 ans en milieu rural de la province du Houet. Sciences et techniques, Sciences de la santé 2004, 27:1.

18. Ralamboson D: Evolution du paludisme à Madagascar et lutte antipalustre. Annales de l'Université de Madagascar 1964, 2:123-133.

19. Randrianarivelojosia M, Harisoa JL, Rabarijaona LP, Raharimalala LA Ranaivo L, Pietra V, Duchemin JB, Rakotomanana F, Robert V, Mauclere $P$, et al.: In vitro sensitivity of Plasmodium falciparum to amodiaquine compared with other major antimalarials in Madagascar. Parassitologia 2002, 44:I4I-I47.

20. Okonkwo PO, Akpala CO, Okafor HU, Mbah AU, Nwaiwu O: Compliance to correct dose of chloroquine in uncomplicated malaria correlates with improvement in the condition of rural Nigerian children. Trans $R$ Soc Trop Med Hyg 200I, 95:320-324.

21. Ariey F, Randrianarivelojosia M, Duchemin JB, Rakotondramarina $D$, Ouledi A, Robert V, Jambou R, Jahevitra M, Andrianantenaina $H$, Raharimalala L, et al: Mapping of a Plasmodium falciparum pfert K76T mutation: a useful strategy for controlling chloroquine resistance in Madagascar. J Infect Dis 2002, 185:710-7/2.

22. Raharimalala AL, Randrianarivelojosia M, Randriamanantena A, Ranarivelo LA, Jaureguiberry S, Rason MA, Rakotomalala E, Ariey $F$ : [Chemosensitivity of Plasmodium falciparum in Sainte Marie island, east coast of Madagascar: in vivo and in vitro studies]. Arch Inst Pasteur Madagascar 2000, 66:26-31.

23. Randrianarivelojosia M, Fidock DA, Belmonte $O$, Valderramos SG, Mercereau-Puijalon O, Ariey F: First evidence of pfcrt mutant Plasmodium falciparum in Madagascar. Trans $R$ Soc Trop Med Hyg 2006, 100:826-830.
Publish with Biomed Central and every scientist can read your work free of charge

"BioMed Central will be the most significant development for disseminating the results of biomedical research in our lifetime. "

Sir Paul Nurse, Cancer Research UK

Your research papers will be:

- available free of charge to the entire biomedical community

- peer reviewed and published immediately upon acceptance

- cited in PubMed and archived on PubMed Central

- yours - you keep the copyright
BioMedcentral 